\title{
Book Review: Contact Mechanics
}

\author{
Markus Heß* \\ Department of System Dynamics and Friction Physics, Technical University, Berlin, Germany
}

Keywords: normal contact, tangential contact, friction, wear, adhesion, contact of rough surfaces, contact mechanics

\section{A Book Review on Contact Mechanics}

James R. Barber, (Basel: Springer International Publishing), 2018, XVII, 585 pages, ISBN: 978-3-319-70938-3, e-ISBN: 978-3-319-70939-0.

Barber's current work "Contact Mechanics" not only closes the huge gap in specialized book literature that has emerged over the last 30 years since the publication of Johnson's bible (Johnson, 1985). It represents both an outstanding reference book and a didactically excellent prepared textbook suitable for teaching master's degree candidates and PHD students. The following excerpts illustrate these quality attributes.

The book deals mainly with linear elastic contact problems, solving them analytically rather than numerically. The focus has been placed deliberately on (precise and approximate) analytical methods, which are essential for understanding the qualitative and general behavior of contact mechanical systems. Numerical methods such as FEM or BEM can solve complex specific problems, but often mislead the user into losing the overall view of generalized system behavior.

The author provides a wealth of alternative and elegant analytical methods. Some of these methods are missing in the relevant literature, so that even a proven expert in contact mechanics will be surprised. As an example, the approximate methods of Boyer and Fabrikant (Chapter 4) may be mentioned, which can be used for calculating the shape factor within the frictionless normal contact between a rigid flat punch with arbitrary cross section and the elastic half space.

\section{OPEN ACCESS}

Edited and reviewed by: Ken Nakano,

Yokohama National University, Japan

*Correspondence:

Markus Heß

markus.hess@tu-berlin.de

Specialty section:

This article was submitted to

Tribology,

a section of the journal

Frontiers in Mechanical Engineering

Received: 17 August 2018 Accepted: 03 September 2018 Published: 20 September 2018

Citation: Heß M (2018) Book Review: Contact Mechanics. Front. Mech. Eng. 4:11. doi: 10.3389/fmech.2018.00011
Furthermore, Manner's solution (Chapter 6) for two-dimensional frictionless periodic contact problems shall be noted.

Of course, Barber also goes into the common classical methods and explains them with unprecedented precision and clarity. After an introductory chapter on the kinematics of contact, Chapters 2-6 are dedicated to frictionless two- and three-dimensional normal contact problems. Chapters 7-9 deal with contact problems that transmit tangential stresses. These include both normal contact problems without slip and tangential contacts under different loading scenarios. In addition to the classical solution idea of Cattaneo and Mindlin for parabolic tangential contacts, the important Ciavarella-Jäger theorem is included, which allows the solution of almost any tangential contact problem. In a recent book on contact mechanics, adhesive contacts should not be missing and are therefore the subject of Chapter 12. Starting with Bradley's solution between rigid bodies, both the former competitive adhesion theories for elastic bodies (DMT and JKR) are critically discussed as well as more recent theories (Maugis, Double-Hertz) presented. Chapter 13 is very special as it treats contact problems of finite structures such as beams, plates, membranes and shells whose solutions are no longer based on half-space approximation. Practical problems such as a piston ring in a cylinder or a cylindrical shell with a shrink-fit reinforcement ring are exemplary solved. Chapter 14 deals with contact problems of layered media and functionally graded materials. Although the discussion of the limiting cases of indentation of a layer bonded to a half-space can also be found in other textbooks, that of the author differs enormously in terms of detail and clarity of the explanations. The largest chapter (Chapter 16) with 65 pages is dedicated to contact problems 
of rough surfaces. It contains all the essential classical theories, such as Bowden and Tabor's theory of friction, theories based on the bearing area curve, and the famous asperity model theory of Greenwood and Williamson. Naturally, there is no lack of theories for solving contacts of fractal surfaces. Among others, the theory of Majumdar and Bhushan as well as the theory of Persson are discussed. Adhesion, incremental contact stiffness and fluid leakage as well as size effects are taken into account. Impartially, the author presents all the essential theories, including their strengths and weaknesses.

The preparation of the statistical foundations in the previously mentioned chapter shows once again that this book is written by an experienced teacher with exceptional didactics. In this regard, a prime example should be highlighted. In section 8.5 Barber considers an elastic strip that is pressed against a rigid plane by a uniform force per unit length and then a tangential force is applied to one end. First, a monotonically increasing tensile force is assumed, which is subsequently reduced. As a result, the strip is left in a state of residual stress and hence retains some memory of the loading cycle. Any student can easily understand this problem including its solution and thus the way is paved to study the famous work of Mindlin and Deresiewicz (1953).

The carefully elaborated numerous end-of-chapter problems are another indicator of this high quality textbook. Although

\section{REFERENCES}

Gladwell, G. M. (1980). Contact Problems in the Classical Theory of Elasticity. Alphen aan den Rijn: Sijthoff and Noordhoff.

Johnson, K. L. (1985). Contact Mechanics. Cambridge: Cambridge University Press.

Mindlin, R. D., Deresiewicz, H. (1953). Elastic spheres in contact under varying oblique forces. J. Appl. Mech. 20, 327-344.

Conflict of Interest Statement: The author declares that the research was conducted in the absence of any commercial or financial relationships that could be construed as a potential conflict of interest. they vary significantly in scope and difficulty, the author pays close attention to the fact that after studying the associated chapter all problems can be solved independently and without any additional resources. Many problems were inspired by the results of current research papers. In this context, it is somewhat similar to the reference book by Gladwell (1980), which is also limited to elastic contacts and enriched by end-ofchapter problems. However, the study of Gladwell's book requires advanced knowledge in the field of integral transformations, since almost all contact problems are solved in this way. Therefore, it is more a (to be updated) reference book than a textbook.

"Contact Mechanics" by James R. Barber will greatly facilitate the work of many PHD students and prospective researchers, since the widely scattered research contributions of the last 30 years have now been summarized in one specialized book. Furthermore, it serves experienced research scientists both as a reference book and a source of inspirations which will undoubtedly result in new research impulses.

\section{AUTHOR CONTRIBUTIONS}

The author confirms being the sole contributor of this work and has approved it for publication.

Copyright $\odot 2018$ Heß. This is an open-access article distributed under the terms of the Creative Commons Attribution License (CC BY). The use, distribution or reproduction in other forums is permitted, provided the original author(s) and the copyright owner(s) are credited and that the original publication in this journal is cited, in accordance with accepted academic practice. No use, distribution or reproduction is permitted which does not comply with these terms. 